\title{
Motivating Course Completion in Executive Development
}

\author{
http://dx.doi.org/10.3991/ijac.v8i2.4362 \\ David A. Foster \\ ExecOnline, New York, NY, USA
}

\begin{abstract}
An innovative online approach to executive development is described. The approach utilizes asynchronous and synchronous elements, required submission of assignments, and other features resembling those of online college courses. Design of the learning experience, though, has been observant of the various motivations of busy executives. The approach so far has resulted in high rates of course completion.
\end{abstract}

Index Terms - executive development, management training, online learning, persistence

\section{INTRODUCTION}

Most large companies try to be methodical about ensuring competent, effective leadership in their executive ranks. Training/education is one important tool for this, but it can be a challenge to implement successfully, given the numerous demands on executives' time.

Much executive development is conducted internally, but many organizations leverage external resources. Third-party courses for developing executive leadership competencies have mostly fallen into either of two categories:

1) self-paced e-learning courses, created by training companies; or

2) short, intensive, in-person courses, typically hosted by a university business school.

The former category has the merit of convenienceanytime and anywhere-as well as juxtaposition with work activities, which can help highlight the applicability of concepts. The latter category has the merits of more substantive assignments and of focused interactions with peers and mentors.

One new approach to executive development aims to provide the benefits of both approaches. Borrowing from the higher education playbook, this approach provides pure-online courses that incorporate professional facilitation and that combine both asynchronous and synchronous elements. ExecOnline is a provider that has had some early success with such an approach.

The mechanics of ExecOnline's courses have many similarities to those of online university courses. ExecOnline's courses extend over a period of several weeks. Each week demands just a few hours of the participant's time, but requires live group meetings, regular submission of assignment deliverables - and a significant level of challenge. Unlike a university course, though, there are no grades. And instead of text readings, there are specially-prepared recorded lectures and other multimedia.
But perhaps the greatest difference between a university online course and an ExecOnline course lies in the characteristics of the "students." University students have carved out all or a large portion of their current lives to obtaining a degree, and, as alluded, they are motivated by grades.

ExecOnline's course "participants," in contrast, are high-level administrators and business executives with both (a) huge demands on their time, and (b) a keen sense of what uses of that time are productive and which are less so. Unlike university students, further, the majority of them are conscripted by their company's leaders; that is, most did not seek out the honor of taking an ExecOnline course.

Absent the carrot of a degree and the stick of grades, how can such executives be motivated to do the work required in the course, and to complete everything on schedule?

This brief case study focuses on the aspects of course design that have helped achieve high rates of successful completion in ExecOnline's online executive development courses. To understand how this was achieved, first it is necessary to briefly review a fuller range of motivation factors.

\section{A RANGE OF MOTIVATORS}

Some motivation factors for executives are in our control; with some we might only have a degree of influence; and with others we might have none. We can think of motivation factors as falling into three categories:

1. External Motivators

- Professional: prospect of attaining certification and status

- Organizational: concern about looking like a team player, and/or about satisfying superiors

2. Internal Motivators

- Rational assessment: expectation that training will enhance professional effectiveness or yield other personal benefits

- Personal passion: intrinsic drive to excel (particularly in self-disciplined personalities)

3. Unconscious Motivators

- Enjoyment: positive experiences draw one in to continued engagement

- Psychosocial convention: every one of us grows up complying with the "school script" 
This is not necessarily an exhaustive list, but it illustrates a broad range of opportunities to engage executive participants via thoughtful course design.

\section{EXECONLINE'S COURSES}

\section{A. Course Topics}

ExecOnline partners with executive education programs at university business schools; it co-develops online courses with them; it markets those courses; and it runs the courses. In contrast with many third-party providers' "open enrollment" sales model, ExecOnline sells blocks of seats directly to corporations. As a kind of intermediary between business school faculty and corporations, ExecOnline provides a learning management platform, significant instructional design resources, and management of participants' experience.

Course topics relate to the challenges faced by organizational leaders, such as formulating strategy, fostering innovation, and improving operations. The ultimate aim of the courses is to help executives to effectively initiate change in their respective organizations. To this end, practical tools are provided in the courses, and, for their projects, executives must select opportunities or challenges in their organizations and apply those tools to them.

\section{B. Components of the Course Experience}

There are several fundamental components to the course experience:

- a project that each participant must define as a "personal case study" from their own organization;

- regular assignment submissions related to their personal case;

- "enhanced" recorded lectures, incorporating carefully-designed visuals, and accessed asynchronously via the web;

- $\quad$ required synchronous videoconference meetings with peers, coaches, and faculty; and

- help desk and other support.

Courses typically run for a six-week period, requiring four to six hours of work each week. Executives who go through the entire course and successfully complete their personal case projects are awarded a certificate from the business school.

At the beginning of each course, every executive is assigned to a learning team and to an individual partner within that team. The teams provide an opportunity for discussion and mutual feedback, and partners can provide one another more detailed feedback and "moral support." Participants also have the option of obtaining feedback from an executive coach.

The assignments typically contribute to a final project deliverable for the course. For example, in a course on Corporate Strategy, each of the first five weeks has an assignment deliverable that must be submitted to the learning management platform. The deliverables are components of a final strategy presentation, including: a structured analysis of the current corporate situation; articulation of strategic choices; and identification of key organizational aspects requiring realignment. Weekly deliverables are shared amongst learning team members. The final strategy presentation in this instance is complet- ed in the sixth week, and is the culmination of the executives' personal case study for the course. Most executives have had the opportunity to present their projects internally at their companies at the end of the course.

\section{Design Process}

The assignments and lecture segments in each course are designed collaboratively between ExecOnline's instructional design team and the professors.

Each lecture segment is a small (5-15 minutes) recorded chunk. After planning and then shooting in the studio, accompanying "slides" are designed and synchronized with the video (Figure 1). Slide content is highly graphical and updates frequently. The outputs of the design process are simple animations that help remote executives maintain focus and comprehension of what the professor is explaining. These mitigate an inherent challenge of remote learning, namely: participants lack the psychological "immediacy" of the professor's physical presence, which naturally makes them more prone to getting distracted.

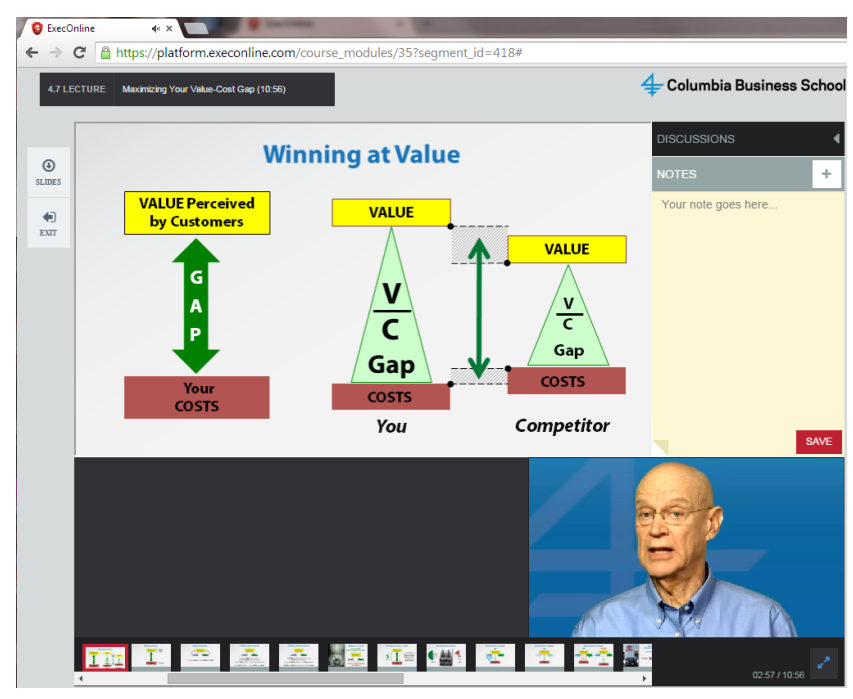

Figure 1. Sample lecture segment.

\section{RELATION OF MOTIVATING FACTORS TO OVERALl DESIGN}

Finally, let us discuss the design of the course experience in view of the motivating factors listed earlier. As it designs courses, ExecOnline aims to be very conscious of the real and pragmatic issues surrounding high-level executives. The approach has proved its effectiveness; in particular, an average of $90 \%$ of those who have started an ExecOnline course have completed it successfully and have received certification from the partner university program.

Enjoyment. Obviously, good instructional design is central to an experience that is fun and engaging. Our courses employ methods such as:

- high-production-value lecture "animations" that are engrossing, lucid, and can be productively consumed with relatively less energy;

- $\quad$ spirited interactions with fellow executives and with coaches; and

- thought-leading, actionable concepts that are developed ever more deeply throughout the course by charismatic management professors. 
Personal passion. In view of who these executives are and what they have already achieved in their careers, it is generally safe to assume that most or all of them have "driven" personalities. They are competitive and are intent on succeeding at whatever they do.

The way that we try to amplify this motivator is by making participants' activities visible to everyone else, with things like progress leaderboards and awards presented at plenary meetings. When people who are driven by success see others striving to succeed and excel in the same venue, it plays on their natural competitiveness.

Psychosocial convention. The courses are challenging, and busy executives encounter no shortage of compelling reasons to procrastinate course work. And, unlike onsite executive education sessions where participants are "trapped in the room," we do not have much control over our executives' time and attention.

Perhaps surprisingly, though, there are ways to exploit deep patterns of habit which cognitive scientists refer to as scripts [1]. Simply by making the course "feel" like a college course, that desired "school script" is mentally activated, and participants unconsciously comply with its requirements.

For example, requiring regular submission of assignment deliverables, with prominent, sternly-worded due dates, has so far had the effect of getting most of the executives to keep up with the pace of the course. Few think to ask the question, "Or else, what?"

Status. As indicated, successful completion of the course leads to a certificate from the business school. No doubt, the more prestigious the university, the more valuable the certification.

As evidence of perceived value, at least some executives who have completed a course have listed their certificates on their personal LinkedIn pages.

Organizational. It would be naïve to imagine that executives are not motivated by political relationships within their organization. When an executive looks at our course, her attitude depends greatly upon the local organizational culture and upon expectations that have been (or might not have been) been communicated. Commonly, the recommendation - or, order-to take the course comes from HR leadership in cooperation with the executive's immediate superior. Such executives know that they should comply, with at least an outwardly positive demeanor. Their true commitment to the experience, though, is not automatically assured.

As part of program design and management, ExecOnline provides guidance to company leadership about how best to prepare executives for the experience, and to properly direct their expectations. If executives are clear about the company's hopes for impactful outcomes, those executives' participation in the course will be more consistent and focused-to say nothing of the positive impacts that are enabled for the organization itself.

Rational assessment. There are a wealth of factors contributing to the executive's assessment of the value of the course's ideas and experience, including:
- the design tactic of clearly describing the course's learning outcomes to the participant and of establishing early evidence in the executive's first few hours of the course that the course is going to be high quality, interesting, and worthwhile;

- intimation that enrollment in the course is a sign from top management that they are being groomed for leadership at the company;

- the fact that their company has bought blocks of seats adds legitimacy and an expectation that others in the corporation will be using shared concepts; and

- the reputation and accomplishments of the course faculty leading to an expectation that they are going to learn proven, leading-edge principles and methods.

Because of its personal relevance, the design element that may have the most impact on their assessment of personal benefit is the personal case project. Going into the course, executives know that what is going to be learned will be immediately applied. They quickly see that initial assignments powerfully demonstrate the applicability of the knowledge and tools, and they have an awareness that the company is encouraging executives to lead initiatives after the course. All of these can help convince the executive that the effort will have a large personal payoff.

\section{CONClusion}

There are a number of useful design techniques that can help motivate busy executives to successfully complete online executive-development courses. ExecOnline has employed many such techniques, and continues to experiment with others.

So far, the approach has achieved a measure of success. In sharp contrast with online MOOCs, an average of $90 \%$ of those who have started an ExecOnline course have completed it successfully and have received certification from the partner university program.

If success rates like these become more widely recognized, it bodes well for the future of using an onlineeducation approach for executive development - an approach with the potential to offer convenience, engagement, and impact.

\section{REFERENCES}

[1] R.C. Schank and R.P. Abelson, Scripts, Plans, Goals, and Understanding: An Inquiry Into Human Knowledge Structures. Hillsdale, NJ: Lawrence Erlbaum Associates 1977.

\section{AUTHOR}

David A. Foster, Ph.D. is Chief Academic Officer with ExecOnline, New York, NY 10016 USA (e-mail: dfoster@execonline.com).

Submitted, December 31, 2014. Published as resubmitted by the author 02 June 2015. 